\title{
Comunicação/Communication
}

\section{Destruição de larvas infectantes de Strongyloides venezuelensis pelos fungos Duddingtonia flagrans, Arthrobotrys robusta e Monacrosporium sinense}

\author{
Destruction of Strongyloides venezuelensis infective larvae by fungi Duddingtonia flagrans, \\ Arthrobotrys robusta and Monacrosporium sinense
}

\begin{abstract}
Fabio Ribeiro Braga ${ }^{1}$, Juliana Milani Araujo ${ }^{1}$, André Ricardo e Silva ${ }^{1}$, Jackson Victor de Araújo ${ }^{1}$, Rogério Oliva Carvalho ${ }^{1}$, Alexandre de Oliveira Tavela ${ }^{1}$, Manoel Eduardo da Silva ${ }^{1}$, Fernanda Mara Fernandes ${ }^{1}$ e Alan Lane de Melo ${ }^{2}$
\end{abstract}

\begin{abstract}
RESUMO
Introdução: Strongyloides venezuelensis tem sido utilizado como um modelo para estudo da estrongiloidose humana. Métodos: O objetivo deste trabalho foi comparar a capacidade predatória dos fungos nematófagos Duddingtonia flagrans (AC001), Arthrobotrys robusta (I-31) e Monacrosporium sinense (SF53) sobre larvas infectantes $\left(\mathrm{L}_{3}\right)$ de Strongyloides venezuelensis em condições laboratoriais no meio ágar-água $2 \%$. Resultados: Ao final do experimento, os percentuais de redução de $\mathrm{L}_{3}$ de Strongyloides venezuelensis observados foram de: 93\% (AC001); 77,2\% (I-31) e 65,2\% (SF53). Conclusões: Os fungos nematófagos foram capazes de capturar e destruir in vitro as $\mathrm{L}_{3}$, podendo ser utilizados como controladores biológicos de Strongyloides venezuelensis.

Palavras-chaves: Fungos nematófagos. Strongyloides venezuelensis. Controle biológico.
\end{abstract}

\begin{abstract}
Introduction: Strongyloides venezuelensis has been used as a model for studying human strongyloidosis. Methods: This study aimed to compare the ability of predatory nematophagous fungi Duddingtonia flagrans (AC001), Arthrobotrys robusta (I-31) and Monacrosporium sinense (SF53) and on infective larvae $\left(\mathrm{L}_{3}\right)$ of Strongyloides venezuelensis in laboratory conditions on $2 \%$ water-agar medium. Results: At the end of the experiment, the percentage reductions of Strongyloides venezuelensi $\mathrm{L}_{3}$ were: $93 \%$ (AC001), $77.2 \%$ (I-31) and $65.2 \%$ (SF53). Conclusions: The nematophagous fungi were able to capture and destroy the $\mathrm{L}_{3}$ in vitro and can be used as biological controllers of Strongyloides venezuelensi.
\end{abstract}

Keywords: Nematophagous fungi. Strongyloides venezuelensis. Biological control.

Entre os nematoides, parasitas intestinais de grande impacto na saúde pública e animal, estão os do gênero Strongyloides ${ }^{1}$. O nematoide Strongyloides stercoralis é o causador da estrongiloidose humana, importante problema médico e social que atinge até 100 milhões de pessoas em cerca de 70 países, sendo a maioria desses localizados em regiões tropicais e subtropicais da Ásia, África e America Latina². O Strongyloides venezuelensis possui ciclo pulmonar infectando roedores e possui uma rota de migração pela via clássica através da corrente

1. Departamento de Veterinária, Universidade Federal de Viçosa, Viçosa, MG. 2. Departamento de Parasitologia, Instituto de Ciências Biológicas, Universidade Federal de Minas Gerais, Belo Horizonte, MG.

Endereço para correspondência: Dr. Fabio Ribeiro Braga. Dept ${ }^{\circ}$ de Veterinária/UFV. Av. Ph Rolfes s/n, 36570-000 Viçosa, MG.

Tel: 5531 3899-1458.

e-mail: fabioribeirobraga@hotmail.com

Recebido para publicação em 25/06/2010

Aceito em 04/08/2010 sanguínea aos pulmões e para o intestino delgado, semelhante ao de Strongyloides stercoralis em humanos. O desenvolvimento de Strongyloides stercoralis e Strongyloides venezuelensis ocorre no ambiente (ciclo de vida livre) e no hospedeiro (ciclo de vida parasitária). A fase parasitária inicia-se com a penetração das larvas filarióides $\left(\mathrm{L}_{3}\right)$ através da mucosa e da pele, e chegam ao intestino delgado onde atingem a maturidade. $O$ parasita é eliminado através das fezes do hospedeiro na forma de ovos e/ou larvas rabditóides. Essa via de infecção é similar a vários geo-helmintos que infectam o homem, tais como Ancylostoma duodenale e Necator americanus ${ }^{3}$. Pesquisas demonstram que Strongyloides venezuelensis tem sido utilizado para padronizar novas técnicas imunológicas, com a finalidade de se aperfeiçoar o diagnóstico da estrongiloidose humana ${ }^{4}$.

A estrongiloidose é uma infecção causada pelo contato do indivíduo com as $\mathrm{L}_{3}$ presentes no ambiente, podendo ser facilmente evitada pelo tratamento adequado do material fecal. Segundo Paulino e cols ${ }^{5}$, tal processo constitui um dos problemas sanitários de maior importância. Sendo assim, medidas alternativas de controle são importantes e, dentre elas, estão o uso de fungos nematófagos presentes no meio ambiente, como uma alternativa viável e cuja ação está concentrada no ambiente fecal e direcionada ao combate dos ovos, e o uso das larvas infectantes dos geo-helmintos ${ }^{6}$.

Diversos antagonistas naturais de nematoides, entre eles, bactérias, vírus, protozoários, besouros, ácaros e fungos, são descritos como controladores biológicos em potencial ${ }^{7}$. Contudo, os fungos nematófagos têm apresentado resultados promissores no combate aos geo-helmintos presentes no ambiente contaminado. As espécies de fungos nematófagos Duddingtonia flagrans, Arthrobotrys robusta e Monacrosporium sinense são identificadas como predadoras e têm sido estudadas como agentes controladores biológicos de nematoides potencialmente zoonóticos, entretanto, podem existir diferenças no mecanismo de ação desses fungos sobre os distintos gêneros de nematoides ${ }^{8}$, por isso a necessidade de mais estudos.

O objetivo deste trabalho foi comparar a capacidade predatória in vitro, dos fungos das espécies Duddingtonia flagrans, Arthrobotrys robusta e Monacrosporium sinense sobre larvas infectantes de Strongyloides venezuelensis.

Foram utilizados três isolados de fungos nematófagos, um de Duddingtonia flagrans (AC001), um de Arthrobotrys robusta (I31) e um de Monacrosporium sinense (SF53). Esses isolados são oriundos de solo do Brasil, na localidade de Viçosa na zona da mata 
de Minas Gerais, e são provenientes do Laboratório de Parasitologia da Universidade Federal de Viçosa. Os fungos foram mantidos em tubos de ensaio a $4{ }^{\circ} \mathrm{C}$, contendo corn-meal-ágar $2 \%$ e no escuro durante 10 dias. Após o crescimento dos isolados, novos discos de cultura de $4 \mathrm{~mm}$ de diâmetro foram transferidos para placas de Petri de $9,0 \mathrm{~cm}$ de diâmetro contendo $20 \mathrm{~mL}$ de agar-água $2 \%$ (AA $2 \%$ ) onde foram acrescidos de $1 \mathrm{~mL}$ de água destilada contendo 1.000 larvas de Panagrellus sp, nematoide de vida livre, diariamente durante um período de 21 dias para indução da formação de conídios fúngicos. Quando se observou o completo desenvolvimento fúngico, $5 \mathrm{~mL}$ de água destilada foram adicionados a cada placa de Petri, sendo que os conídios e fragmentos miceliais foram removidos segundo a técnica descrita por Araújo e cols?

Coproculturas realizadas com fezes de camundongos da linhagem AKR/J experimentalmente infectados com Strongyloides venezuelensis foram colocadas em aparelho de Baermann modificado para a recuperação das $\mathrm{L}_{3}^{10}$. A linhagem de Strongyloides venezuelensis utilizada neste estudo vem sendo mantida em camundongos AKR/J, com passagens sucessivas desde 1987 em condições laboratoriais ${ }^{11}$. A seguir, realizou-se o teste de predação em superfície de placas de Petri de $9 \mathrm{~cm}$ de diâmetro preenchidas com AA $2 \%$ de acordo com técnica modificada por Mota e cols ${ }^{12}$. Foram formados quatro grupos, três grupos tratados com os fungos e um grupo controle (sem fungos). Nas placas de Petri, foram vertidos $0,1 \mathrm{~mL}$ de solução contendo $5 \times 10^{3}$ conídios por ml (500 conídios) de cada fungo AC001, I-31, SF53 e 500L de Strongyloides venezuelensis em cada grupo tratado. As placas do grupo controle receberam apenas $500 \mathrm{~L}_{3}$ de Strongyloides venezuelensis na superfície das placas de Petri. Foram realizadas seis repetições para cada grupo. Durante sete dias, a cada $24 \mathrm{~h}, 10$ campos aleatórios de $4 \mathrm{~mm}$ de diâmetro em cada placa dos grupos tratados e controle foram observados em microscópio óptico em objetiva de $10 x$, contando-se o número de $\mathrm{L}_{3}$ não predadas. Ao final de sete dias, foram recuperadas as $\mathrm{L}_{3}$ não predadas do conteúdo das placas de Petri através do aparelho de Baermann com água a $42^{\circ} \mathrm{C}$. A média de $\mathrm{L}_{3} \mathrm{de}$ Strongyloides venezuelensis recuperadas foi calculada. Os dados foram interpretados estatisticamente pela análise de variância em níveis de significância de $5 \%$ de probabilidade.

A eficiência de predação de $\mathrm{L}_{3}$ em relação ao controle foi avaliada pelo teste de Tukey ao nível de $1 \%$ de probabilidade. Posteriormente, o percentual de redução da média de $\mathrm{L}_{3}$ foi calculado de acordo com seguinte equação:

$\%$ Redução $=\left(\right.$ média de $\mathrm{L}_{3}$ recuperadas do controle - médias de $\mathrm{L}_{3}$ recuperadas do tratamento $)$ x 100 média de $\mathrm{L}_{3}$ recuperadas do controle

No presente ensaio in vitro, os isolados dos fungos predadores de nematóides testados, Duddingtonia flagrans (AC001), Arthrobotrys robusta (I-31) e Monacrosporium sinense (SF53) foram capazes de predar as $\mathrm{L}_{3}$ de Strongyloides venezuelensis. Comparando a captura e destruição de $\mathrm{L}_{3}$ de Strongyloides venezuelensis nas placas de Petri dos grupos tratados com os isolados AC001, I-31 e SF53, durante sete dias a cada $24 \mathrm{~h}$ foi observado que não houve diferença $(\mathrm{p}>0,05)$, conforme descrito na Tabela 1. Diferença $(p<0,05)$ foi observada entre as médias de $\mathrm{L}_{3}$ de Strongyloides venezuelensis não predadas por campo de $4 \mathrm{~mm}$ de diâmetro das placas do grupo controle em relação as médias de $\mathrm{L}_{3}$ registradas nas placas dos grupos tratados com fungos durante todo o experimento.

Foram observados os seguintes percentuais de redução de $\mathrm{L}_{3}$ de S. venezuelensis: 93\% (AC001); 77,2\% (I-31) e 65,2\% (SF53). A presença das $\mathrm{L}_{3}$ de Strongyloides venezuelensis nas placas de Petri contendo AA2\% foi essencial para a formação das armadilhas pelos isolados fúngicos, uma vez que, esse meio de cultura é pobre em nutrientes (Figuras 1A e B). Nas placas do grupo controle, apenas foram observadas a presença de $\mathrm{L}_{3}$ de Strongyloides venezuelensis.

TABELA 1 - Média diária e $( \pm)$ desvios padrão de larvas infectantes $\left(\mathrm{L}_{3}\right)$ não predadas de Strongyloides venezuelensis durante o período de sete dias nos grupos tratados com os fungos (AC001, I-31, SF53) e grupo controle (sem fungo).

\begin{tabular}{lccccccc}
\hline & \multicolumn{7}{c}{ Tempo (dias) } \\
\cline { 2 - 7 } Fungos & 1 & 2 & 3 & 4 & 5 & 6 & 7 \\
\hline AC001 & $1,6^{\mathrm{A}} \pm 0,8$ & $1,3^{\mathrm{A}} \pm 0,69$ & $1,1^{\mathrm{A}} \pm 0,2$ & $0,8^{\mathrm{A}, \mathrm{B}} \pm 0,7$ & $0,6^{\mathrm{A}} \pm 0,5$ & $0,5^{\mathrm{A}} \pm 0,6$ & $0,3^{\mathrm{A}} \pm 0,6$ \\
I-31 & $2,2^{\mathrm{A}} \pm 0,9$ & $1,9^{\mathrm{A}} \pm 1,2$ & $1,0^{\mathrm{A}} \pm 0,6$ & $0,9^{\mathrm{A}} \pm 0,6$ & $0,8^{\mathrm{A}} \pm 0,6$ & $0,5^{\mathrm{A}} \pm 0,5$ & $0,4^{\mathrm{A}} \pm 0,7$ \\
SF53 & $2,8^{\mathrm{A}} \pm 1,2$ & $2,2^{\mathrm{A}} \pm 1,1$ & $1,4^{\mathrm{A}} \pm 0,8$ & $1,2^{\mathrm{A}} \pm 0,6$ & $1,0^{\mathrm{A}} \pm 0,5$ & $0,6^{\mathrm{A}} \pm 0,6$ & $0,6^{\mathrm{A}} \pm 0,8$ \\
Controle & $11,6^{\mathrm{B}} \pm 8,5$ & $11,6^{\mathrm{B}} \pm 8,1$ & $9,5^{\mathrm{B}} \pm 4,8$ & $8,5^{\mathrm{B}} \pm 3,2$ & $9,0^{\mathrm{B}} \pm 3,0$ & $8,2^{\mathrm{B}} \pm 2,3$ & $5,7^{\mathrm{B}} \pm 3,7$ \\
\hline
\end{tabular}

Médias seguidas pela mesma letra maiúscula nas linhas não diferem estatisticamente ( $p>0,01)$ - Teste de Tukey. AC001: Duddingtonia flagrans, I-31: Arthrobotrys robusta, SF53: Monacrosporium sinense.

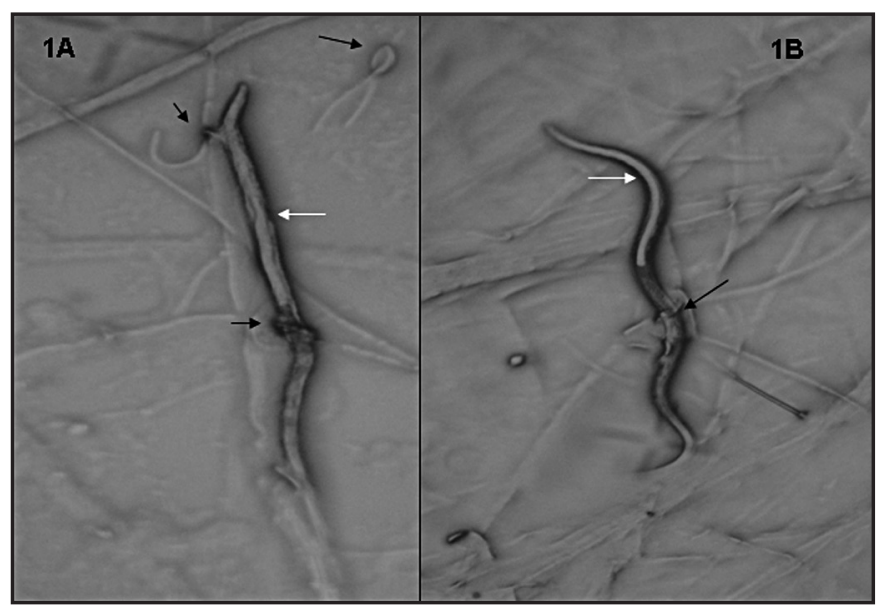

FIGURA 1A/B - Larvas infectantes $\left(\mathrm{L}_{3}\right)$ de Strongyloides venezuelensis (seta branca) e armadilhas de fungos nematófagos (seta preta) aos setes dias. 
A comprovação da predação foi verificada pelas médias de $\mathrm{L}_{3}$ de Strongyloides venezuelensis recuperadas por meio do método de Baermann no sétimo dia ao final do experimento (Figura 2).

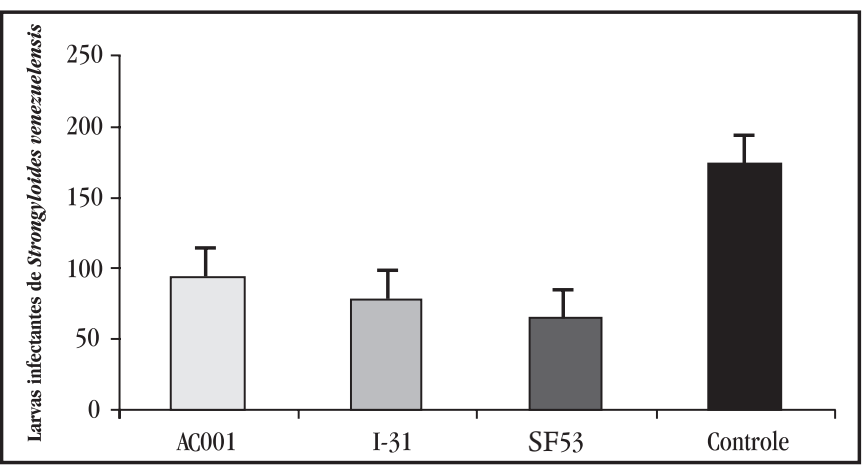

FIGURA 2 - Número de larvas infectantes $\left(\mathrm{L}_{3}\right)$ de Strongyloides venezuelensis não predadas recuperadas no sétimo dia do meio Agar-água 2\% pelo método de Baermann dos tratamentos após interação dos isolados fúngicos $\square$ Duddingtonia flagrans(AC001). $\square$ Arthrobotrys robusta(I-31). $\square$ Monacrosporiumsinense(SF53) e grupo controle. Barra representa o desvio padrão.

Fungos nematófagos possuem capacidade de destruir as $\mathrm{L}_{3}$ de geo-helmintos, com destaque para as espécies Duddingtonia flagrans, Arthrobotrys robusta e Monacrosporium sinense ${ }^{8}$. Todavia, a capacidade predatória dessas espécies nunca tinha sido testada sobre $\mathrm{L}_{3}$ de Strongyloides venezuelensis. Além disso, poucos trabalhos têm mencionado a atividade predatória in vitro de diferentes fungos nematófagos sobre larvas de nematóides do gênero Strongyloides, constituindo a necessidade de maiores pesquisas. Em relação a sua nutrição, esses fungos não são exigentes. Segundo Eren e Pramer ${ }^{13}$, o fornecimento periódico de nematoides aos fungos em meio de cultura pobre em nutrientes, reduziria o seu crescimento saprófita. Dessa forma, no presente trabalho foi utilizado o meio AA $2 \%$, meio pobre em nutrientes, com a intenção de reduzir o crescimento saprófita dos isolados fúngicos utilizando apenas as $\mathrm{L}_{3}$ de Strongyloides venezuelensis como fonte de nutrição. Por outro lado, quanto maior a mobilidade dos nematoides, maior o estímulo ao fungo para a produção de armadilhas. No presente estudo, este fato foi observado, uma vez que, a formação de armadilhas e predação das $\mathrm{L}_{3}$ pelos isolados fúngicos foram visualizadas logo na primeira observação, ocorrido após $24 \mathrm{~h}$ de interação.

Em trabalho recente, Braga e cols ${ }^{8}$ registraram que em meio de cultura AA $2 \%$ o fungo Duddingtonia flagrans demonstrou maior atividade predatória $(80,3 \%)$ sobre $\mathrm{L}_{1}$ de Angiostrongylus vasorum em relação aos demais isolados utilizados, Monacrosporium thaumasium (74,5\%) e Arthrobotrys robusta (71,8\%). Estes resultados estão de acordo com o presente trabalho, uma vez que a maior atividade predatória in vitro observada ao final do experimento sobre $\mathrm{L}_{3}$ de Strongyloides venezuelensis foi para o isolado fúngico de Duddingtonia flagrans (AC001) em meio AA 2\%. No entanto, faz-se necessário a realização de mais pesquisas que possam demonstrar a interação destes e de outros fungos nematófagos sobre $\mathrm{L}_{3}$ de nematoides gastrintestinais ajudando na sua diminuição ambiental e, por conseguinte nas infecções.

Concluiu-se que os fungos Duddingtonia flagrans (AC001), Arthrobotrys robusta (I-31) e Monacrosporium sinense (SF53) têm atividade predatória sobre larvas infectantes Strongyloides venezuelensis e, possivelmente, constituem uma alternativa de controle biológico das $\mathrm{L}_{3}$ desse nematoide.

\section{CONFLITO DE INTERESSE}

Os autores declaram não haver nenhum tipo de conflito de interesse no desenvolvimento do estudo.

\section{SUPORTE FINANCEIRO}

Coordenação de Aperfeiçoamento de Pessoal de Nível Superior (CAPES), Fundação de Amparo à Pesquisa de Minas Gerais (FAPEMIG) e Conselho Nacional de Desenvolvimento Científico e Tecnológico (CNPq).

\section{REFERÊNCIAS}

1. Grove DI. Human strongyloidiasis. Adv Parasitol 1996; 38:251-309.

2. Siddiqui AA, Berk SL. Diagnosis os Strongyloides stercoralis infection. Clin Infect Dis 2001; 33:1040-1047.

3. Ferreira CM, Pereira ATM, Souza RS, Cassali GD, Souza DG, Lemos VS, et al. Prevention of changes in airway function facilitates Strongyloides venezuelensis infection in rats. Microbes Infect 2007; 9:813-820.

4. Machado ER, Ueta MT, Gonçalves-Pires MRF, Oliveira JBA, Faccioli LH, CostaCruz JM. Strongyloides venezuelensis alkaline extract for the diagnosis of human strongyloidiasis by enzyme-linked immunosorbent assay. Mem Inst Oswaldo Cruz 2003; 98:849-851.

5. Paulino RC, Castro EA, Thomaz-Soccol V. Tratamento anaeróbio de esgoto e sua eficiência na redução da viabilidade de ovos de helmintos. Rev Soc Bras Med Trop 2001; 34:421-428.

6. Frassy LN, Braga FR, Silva AR, Araújo JV, Ferreira SR, Freitas LG. Destruição de ovos de Toxocara canis pelo fungo nematófago Pochonia chlamydosporia. Rev Soc Bras Med Trop 2010; 43:102-104.

7. Mota MA, Campos AK, Araújo JV. Controle biológico de helmintos parasitos de animais: estágio atual e perspectivas futuras. Pesq Vet Bras 2003; 23:93-100.

8. Braga FR, Carvalho RO, Araujo JM, Silva AR, AraújoJV, Lima WS, et al. Predatory activity of the fungi Duddingtonia flagrans, Monacrosporium thaumasium, Monacrosporium sinense and Arthrobotrys robusta on Angiostrongylus vasorum first-stage larvae. J Helminthol 2009; 83:303-308.

9. Araújo JV, Santos MA, Ferraz S, Maia AS. Antagonistic effect of predacious Arthrobotrys fungi on infective Haemonchus placei larvae. J Helminthol 1993; 67:136-138.

10. Barçante JMP, Barçante TA, Dias SRC, Vieira LQ Lima WS, Negrão-Corrêa D. A method to obtain axenic Angiostrongylus vasorum first-stage larvae from dog feces. Parasitol Res 2003; 89:89-93.

11. Melo AL, Martins WA, Bicalho RS. The AKR/J mouse as a laboratory host for maintenance of cycle of Strongyloides ratti. In: International Congress of Laboratory Animal Science. Águas de Lindóia: Col Bras Experimentação. Resumos; 1990. p.72.

12. Mota MA, Campos AK, Araújo JV. Avaliação da capacidade predatória dos fungos Arthrobotrys robusta e Monacrosporium thaumasium sobre nematóides gastrintestinais parasitos de bovinos, submetidos a diferentes métodos de preservação. Rev Bras Parasitol Vet 2002; 11:13-17.

13. Eren J, Pramer D. The most probable number of nematode-trapping fungi in soil Soil Sci 1965; 99:285. 